\title{
Technology-Mediated Learning for Resilience
}

\author{
Tim A. Majchrzak \\ University of Agder, \\ Kristiansand, Norway \\ Email: timam@uia.no
}

\author{
Peter André Busch \\ University of Agder, \\ Kristiansand, Norway \\ Email: peter.a.busch@uia.no
}

\author{
Kjetil Sandvik \\ Department for Media, Cognition and Communication, \\ University of Copenhagen, Denmark \\ Email: sandvik@hum.ku.dk
}

\begin{abstract}
Resilience is a topic of steadily increasing interest. It particularly gains importance when discussing how communities (e.g. municipalities) can prepare themselves for potential future disruptions. A resilient community will overcome immediate shocks, such as an earthquake, as well as stresses, such as the successive outbreak of a pandemic. Due to the novelty of the topic, research particularly exists on theoretical aspects of resilience. Targeting learning - and thereby the local population - is a rather new emergence. To effectively reach, involve, and engage citizens, technology can play a key role. Based on four actual cases from communities we analyse the impact technology has on learning about resilience. We then scrutinize the effectiveness and propose future steps. Thereby, we seek to provide practical advice to local governments and to enrich the theory at the same time.
\end{abstract}

\section{Introduction}

Municipalities as well as societies face many threats and challenges. They need to cope with shocks - sudden, disruptive events such as natural disasters and terrorist attacks - and with stresses - long-term developments that endanger stability, such as large migratory movements [1]. Therefore, resilience has gained increasing interest. Resilience describes the ability of a system to withstand disruptions and to return to a stable state [2]. Imagine for example an intensive earthquake: Will a city be devastated or mostly withstand it? If it is devastated, can it be rebuilt quickly? Alternatively, imagine many refugees arriving in a municipality. Will they integrate with the local population and become happy citizens? Or will they be segregated, possibly even forming a kind of ghetto? In both cases, a high level of resilience would mean that the challenges can be handled and the exante situation might even be better than the a-priori one.

Resilience has received much attention as a research topic (cf. e.g. [3], [4], [5], [6]). However, some areas of research are better covered than others. There is much academic and institutional (e.g. by cities) interest but little work on how topics of resilience can be taught. However, after all it is people that make a city, a municipality, and a society resilient [1]. This aligns with research in fields like crisis management, where the importance of people is stressed [7], [8]. Thus, we think that learning and education about resilience should gain more attention.

To stimulate this attention and to help close the research gap, we work with partners from science and practice in a project that focusses on societal learning. The project was initiated in 2016. To target the local population and to support local governments, four cases spanning Iceland, one Baltic country, and two Scandinavian countries are developed. While the general topic of the project was deliberately left broad, all cases are unified in that they strive to educate and to facilitate learning. Moreover, all fall under the umbrella of resilience where the intention is to empower citizens to be able to work with change, difference, and uncertainty. All the cases seek to mediate the learning experience by using innovative technology for mediation. At the same time, the actual target groups of the cases are quite different. The same applies to the content and the design of the cases.

In this paper, we introduce the four cases as a foundation to argue for the need of extended activities in the interplay of technology and learning for the societal benefit. Since we tackle a novel topic, we also carefully explain the related, multifaceted background. Our work is not purely theoretic, though, but we embed a study we conducted with the case makers to reflect on their endeavours. We not only provide the necessary context for a generalization of findings but also scrutinize the effectiveness. Our work has some limitations. Since this paper is the first one we publish on the topic and the cases have a work-in-progress status, much space is allocated to explain the background and underpinning of the project and less space is attributed to findings. Future papers will aim at describing methods and practices for lifelong learning that could be used by others.

Our paper makes several contributions. First, we introduce four innovative research cases that address a novel topic, each from a unique perspective. Second, we present empirical results from the work with practitioners with a background in education. Third, we propose which lessons can be learned from our work.

The remainder is structured as follows. Section 2 explains the background of our work, followed by Section 3 that 
discuss related work in detail. In Section 4 we illustrate the four cases that form the foundation of this paper. We then present empirical results in Section 5. In Section 6 we discuss the results before drawing a conclusion in Section 7.

\section{Background}

In the following, we introduce our research project. We then illustrate our research design, including data collection.

\subsection{About the Project}

The project that our research originates from - The Learning Society - is located in Scandinavia and the Baltic. It was initiated in 2016 as a kind of follow-up brainchild from a large project that targets urban resilience. Our consortium consists of three academic institutions and three cities respectively municipal organizations. We span Iceland, one Baltic country, and two Scandinavian countries.

The general topic of the project was deliberately left broad. It ought to create a collaborative network of partners that seek to improve societal learning. A local government focus was envisioned. While not targeting the topic of egovernment directly, the initiative for the practical contributions to the project are led by local governments. Resilience was targeted as the unifier for four cases to be developed (three by the cities, one by the partner from Iceland for the application in adult education). The four cases will be introduced in Section 4 along with additional information on their background.

As a topic, the project combines the idea of societal learning with the intention to support governmental work by educating citizens. It was decided that education should not be meant in a top-down, indoctrinating sense, but rather as an empowerment of citizens who become aware that they can make the proverbial change.

While discussing the early steps of the creation of the cases, it became apparent that not only the focus on learning with the aim of resilience was a unifier, but the cases could have one additional common denominator. All project partners have an interest in technology-mediation, or more generally, technology use in learning. This includes but is not limited to e-learning and the application of novel hardware for experimental, "unusual" work (e.g. tinkering [9]). Therefore, scrutinizing which role technology can play has early become a part of the project. It also is helpful since the cases now have conceptually much in common despite profound content varieties.

Whereas the cases have a deliberate practical-focus, the two scientific partners not acting as case makers were intended as the academic "counterweights". The task is to help the case makers envision, design, deploy, and evaluate the cases, and specifically to keep the focus on resilience. Moreover, whereas the dissemination within the cities resides with the case makers, the scientific partners seek to disseminate the insights and to transport feedback gained through scientific work back to the project. The latter task is also an additional aim with writing this paper.

\subsection{Research Method}

Taking into account the novelty of the topic of interest, a multiple case replication design was selected. A multiple case study is suitable to collect rich data and investigate a phenomenon in different contexts [10]. A theoretical replication is applied where each case is expected to yield somewhat contrasting results. In total, four case organizations were studied. These are described in Section 4. Each case organization represent one societal initiative that aim to learn citizens about resilience.

The procedure of our work can be described as follows. We engaged in discussions with the case makers from the beginning of the project on. As the general direction of the cases became obvious, we developed an abstract (suggestion our ideas, but of course not yet indicating any results) for a reach paper, proposing our ideas for research. After iterating the abstract a few times, we started our theoretical work while the case makers continued building their cases. We then provided them with the questionnaire and collected the replies shortly after. This paper combines the observations from the project, the description of the cases, and the analysis of the questionnaire results.

For data collection, three researchers engaged in overt participant observations in meetings, online labs, and web forums during the project planning phase (approx. one year). Participant observation is suitable to gain in-depth knowledge of the cases and in what the project members do. The researchers used their senses to observe behaviour as well as collecting data from documents and other online writings. Meetings and online labs were scheduled by the project manager in advance, and led by different people in the project based on their role. Data from the online labs, and web forums are electronically available to all project participants. Thereby, the project builds a knowledge base in form of a diary, from which we can draw for research. It is helpful that this gives a chronological picture. Notes from the meetings were written down. No utterances were written down verbatim but instead the essence was captured.

Standard grounded theory techniques were used to analyse the data [11]. Findings were analysed both within case and between cases [12], [10]. We cycled among data and relevant literature to develop a thorough understanding of the impact technology has on learning about resilience. As the initial step, field notes, documents, and online writings were analysed using open coding. The coding was based on the language used by the project members in their writings and the field notes from the participatory observations. 


\section{Related Work}

Much research is conducted on resilience and e-learning as separate fields of interest. However, literature focusing on how technology promotes learning about resilience is scarce.

\subsection{Resilience}

Lately, a transition from risk management (mitigating known risks) to resilience (accounting for the unexpected) has been observed in the literature [13]. Resilience as a concept is often associated with the attributes strength and flexibility. A tree and grass can be used to illustrate these attributes. While a tree has a very hard stem that will endure severe impact, grass will quickly bend altering its shape. However, if the tree and the grass are exposed to very heavy wind blows, the tree might fall and its stem break whereas the grass will still bend but not break. While there is no way for the tree to recover from this event, the grass will eventually return to its former shape and position.

Resilience as a concept appears in several disciplines such as psychology [14], software engineering [15], and organization science [16]. In psychology, the basic idea is to master your life despite hardships and adverse circumstances. In software engineering, resilience focuses on how software can recover from unforeseen events. In organization science, organizations need to become resilient to overcome stresses and shocks in the environment and to ensure continuity and future competitiveness.

Social resilience is a rather new perspective where the concept is commonly understood as "the ability of a [...] society exposed to hazards to resist, absorb, accommodate to and recover from the effects of a hazard in a timely and efficient manner, including through the preservation and restoration of its essential basic structures and functions" [17]. Most research on technology and resilience has focused on how technology can assist citizens during an emergency, and how technology can help emergency personnel communicate between themselves and to citizens and other stakeholders [7], [18].

\subsection{E-learning}

While the area of e-learning has attracted researchers from diverse disciplines such as information systems, management, and educational psychology, the understanding of what the concept means is not clear. This can be illustrated by the frequent use of many similar terms such as computerbased learning, online learning, distance learning, and distributed learning. E-learning evolves constantly, and new technologies and applications can introduce new capabilities making it difficult to define what e-learning is. In this paper, we understand e-learning as the use of technology, most dominantly through the Internet, to facilitate the creation of knowledge and expertise among groups and individuals [19]. This broad definition allows us to study e-learning in various contexts using different types of innovative technology.

E-learning systems are routinely used in schools and organizations. Statistics from the US show that hundreds of thousands of students have been enrolled in online courses, and that the number of minority students and students above 26 years of age is high [20]. While e-learning is often used by educational institutions, similar initiatives by communities with the purpose to reach, involve, and engage citizens are - to our observations - less common.

Traditionally, e-learning has been viewed as both asynchronous and synchronous in nature [21]. Asynchronous elearning is directed one way - from teacher to learner pre-recorded, and often available at any time of the day and from any location. Asynchronous applications can range from the less sophisticated such as Microsoft PowerPoint slides posted in a learning management system (LMS) (cf. e.g. [22]) to online simulations and tools that require learner involvement. Synchronous e-learning has gained more momentum in the last decade (cf. e.g. [23]), and refers to learning with scheduled arrangements where students and teachers can interact with each other in real-time. Recent developments include social networking software [24], [25], , gamification [26], visualization [27], moderated and userfocused E-Learning content, and mobile learning [28].

Systems for e-learning are associated with numerous advantages such as providing consistent learning across separate locations yet with the possibility of individual customization, reducing delivery cycle time, increasing learner convenience, providing access to specialized expertise, and lowering expenses [29] [30]. E-learning appeals to societies that have a need to teach masses in a relatively short time frame and within limited budgets. However, also relatively complex tasks such as assessment of non-trivial assignments has become possible (cf. e.g. [31]). Among the disadvantages of e-learning systems are up-front investment costs, the need for students to be extra motivated, and the strong need for pedagogical planning to become successful [29].

\subsection{Learning about Resilience through Technology}

Most research on technology and resilience has focused on how technology can assist citizens during an emergency, and how technology can help emergency personnel communicate between themselves and to citizens and other stakeholders [32].

However, we will argue that we need a broader approach to what teaching and learning technologies are. Moreover, we need to find ways in which these technologies not only function as means for communicating about resilience, but enable learning formats. These should prime the learners in ways that also make them resilient learners. Thus, the aim is empowering them to partake in problem-solution and 
knowledge-creating (and now just knowledge-transferring) learning processes (see [33]). It is imperative to have a keen eye on how the teaching and learning technologies are used: from the traditional class-room to online learning systems; from ways of augmenting off-line learning environments to constructing environments consisting of blending online and offline technologies; or flipping back and forth between different technologies.

One place to point our attention when it comes to uses of technology in learning about resilience or even learning about how to become resilient could be on technologyenhanced creative learning environments, so-called makerspaces. They are employed in various settings such as pre-schools, schools, libraries, museums and more informal learning environments (third places, see e.g. [34]) such as after school clubs. It needs to be scrutinized whether these are conceived as a continuation of the school day - this applies particularly to spaces for other types of learning activities e.g. in the shape of making and tinkering but still in designed formalized learning processes. Alternatively, they may be understood more in lines of out-of-school, not just implying the change of localities from class room to workshop facilities etc., but also a break from school: offschool with focus on self-organized activities. Whereas the first understanding of after-school is prevalent in academic literature on makerspaces (focusing on STEM and how makerspaces enable and empower learners in these particular educational efforts), the latter is hardly present.

The bulk of academic works are typically based on (US) case studies and either seeing afterschool makerspaces in connection to formalized learning programs (within the K-12 framework) or out-of-school settings with less focus on formalized learning and being more focused on self-organized activities, communities of interest and so on. In their report Bevan et. al [35] examine how afterschool educators at four different organizations in the US have integrated making into their programs in order to more deeply engage participants with STEM concepts, phenomena, and practices. The report demonstrates how these programs "Build on key characteristics of Making and Tinkering that have been extensively documented in the research literature [36], [9], [37]): It exercises students' creative and improvisational problemsolving abilities; It builds students' agency, persistence, and self-efficacy; It helps students to deepen and complexity their ideas and understanding." [35, p. 2].

\subsection{Resilience as Learning Methods and Practices}

A changing world calls for thinking in resilience strategies. This is true not only when it comes to focusing on tackling challenges (e.g. climate change effects), but also when it comes to educating and communicating knowledge and thus empowering citizens to understand and navigate complexities. Important aspects of this endeavour include how to integrate knowledge in everyday life and the public's abilities to understand and appropriate complex knowledge, as well as the creation of practices in which citizens partake in knowledge-creation and continuous discussions on what knowledge is and what types of knowledge are needed. Knowledge (or science) communication and learning efforts must be inclusive and integrated into existing communities and spaces by ways of various teaching and learning technologies. In this, an important focus must be on how the learning environments come with specific coding (affordances, rituals etc.) and if they can enable engaging and learning community-focused processes.

Learning is related to the environment created for the learning experience. It comes with specific routines and structures, which shape and determine the educational practices. The auditorium and the classroom-like lecture rooms are so dominant at the universities inside specific pedagogical and didactic routines and rituals: Lectures come with specific hierarchical roles ascribed to the lecturer (the provider of knowledge) and the students (the receivers of knowledge) [38]. The routines and rituals embedded in the physical design as well as the pedagogical design of the learning situation may go against ideas about (co-)creating learning environments that are engaging and inspiring and which urge learners to oversee their own learning processes and development. Moreover, they contradict the idea that learning is not (just) about acquiring knowledge, it is also about researching and creating knowledge.

Learning communities is an important aspect where learners are empowered and equipped to be engaged and participating actors in processes of learning and dealing with change, complexify and challenges - the very core of any resilience strategy (cf. Section 3.1). This comes with some requirements [39]:

a "Learning community participants must feel a sense of belonging to the group that drive their desire to keep working and helping others;

b The participants must be in a position to affect what happens in the community;

c A learning community must facilitate meeting needs such as expressing personal opinions, asking for help, or specific information; and

d A learning community must give the participants possibilities to share stories of events with particular issue included emotional experiences."

Thinking in lines of these four requisitions for learning in communities will have bearing on how we construct learning practices and the technologies they are embedded in. Prominent issues are [40]:

a Breaking up the teacher-student hierarchy: in a learning community setting the teacher is not the (sole) "information provider" but a participant facilitating learning;

b Challenging ideas about teaching and learning: from 
acquiring (fixed) knowledge that can be tested/evaluated to engaging in knowledge-production and discussion; Challenging the 'nature' of course planning: adapting to what is important, necessary and interesting to learn;

c Design: how do we organize learning-spaces (online/offline) that ensure learning community processes?;

d Practices: how do we create open and collaborative processes - thinking beyond the traditional scheme?;

e Roles and rituals: giving the students responsibility and empowerment in the learning processes;

f Flows: how are the communication patterns and logics organized: traditional one-way such as asking questions and giving comments vs. multiple-ways such as dialogue and collaborative processes; and finally

g Coding of rooms: a traditional class room a 'stage' for the teacher and tables and chairs for the students in contrast to open spaces where furniture and communication technologies can be arranged to suite the specific learning situation.

In relation to the last point, it is important to consider that online learning environments often remediate offline as well: online lectures (e.g. TED talks) duplicate a traditional classroom setting, online "class rooms" are set up with the same communicative logic as in offline class rooms. This is contrary to conference-setups (like Google Hangout, Adobe Connect...) or online-worlds (like the basic idea of Second Life) with the possibilities of collaborative learning processes.

\section{The Four Cases}

The four cases use technology in different ways to promote resilience varying from teaching kindergarten children about their communities and students about resilience, to letting refugees participate in public debates, and sharing knowledge among municipal consultants to make small societies more resilient.

\subsection{Case 1: Refugees}

The first case focuses on integrating young refugees (including unaccompanied minors) with other youth in a Norwegian city and preparing them for further education or the job market to avoid social exclusion. This is not only seen as a social investment but also as a way to prevent possible radicalization at a very early stage. To solve this task, this case uses a café with six social therapists and four persons in a monitoring team. Moreover, they have engaged citizens as volunteers. These volunteers are intended to get more responsibility for the refugees and their role will shift from being mere helpers to facilitators.

The idea is to team up volunteers with refugees and to stimulate an exchange. Typical teams could be made from volunteers who have specific knowledge that can be helpful for a refugee. Think e.g. of a refugee who started to study chemistry before relocating. He or she could be teamed up with a former employee of a chemistry company, who is now retired. Thereby, the refugee could get up to date to national idiosyncrasies. Ideally, he or she will be able to continue the studies in Norway, or find a job in a company that seeks the specific set of skills. Moreover, the volunteers will likely transport a positive image of the work with refugees back to society.

Case 1 will use social media to enhance the collaboration between employees, volunteers, and refugees, and engage the refugees to participate in social debate. For this purpose, a kind of matchmaking app is to be developed. It will pose calendar functionality, offer volunteers and refugees to register, and help with the linking up. This will unburden the social workers of the city. Moreover, this approach poses a low barrier for young people, who might be reluctant in upfront physical meetings.

\subsection{Case 2: Kindergarten}

The second case is from a Danish municipality. The task at hand for Case 2 is to develop a concept for a flexible, digitized sensory room for kindergartens together with the users of the room; adults and children. The purpose is for small children to be able to learn how a community is developed and to be a part of a community. Learning takes place using an action learning and co-creation approach through experimenting activities. Ideas, information, and reflections will be shared as Instagram pictures and videos. The case builds on prior work with design thinking, experimenting communities, and developing projects with digital devices conducted in kindergartens in the municipality.

The purpose of the project is to provide means to help each other, give everybody a part in society, and use resources of everybody in a community. The outcome is expected to be recommendations on how you can work with flexible sensory rooms in a kindergarten. The recommendations aim to look at possible ways to combine the room, technology, activities, and different ways of allocating groups of children who are in the sensory room at the same time. Technology in this case can be an enabler that lowers the barrier for participating. In other words, the ideas proposed in the text would also work without technology, but with technologymediation they are more effective and more inclusive.

\subsection{Case 3: Adults}

The purpose of the third case is for a group of 12 consultants in various small municipalities in Southern Iceland to learn how to deal with a massive flow of tourists. Tourism is attractive, but the general situation of Iceland needs to be kept in mind. In a country with immense risks of natural disasters combined with infrastructure that is not 
well equipped for a high number of tourists, careful planning is important.

The group uses a digital platform called podio [41] to share information, learning material, and to discuss various challenges related to how the municipalities can become more resilient. The platform can incorporate all kinds of media technology that is relevant to the project. The potential to engage citizens is through teaching citizens in smaller communities how to deal with the challenges of massive tourism, a lack of proper infrastructure, and the consequences of natural disasters.

The challenge of the case lies in the connection of the various topics to facilitate adult education.

\subsection{Case 4: Online Course}

The fourth case develops an online study course to ensure inclusive and equitable quality education and promote lifelong learning opportunities for all. From our four cases, it is the least developed one. The Baltic city creating the course is taking the creation process as a possibility to reflect on what they want to achieve.

Through the course, the students will learn about other countries and their work with resilience. The project will engage five teachers and 24 youngsters in the age of 1718 years. The teachers will initiate the work on the course material and try out the online study before making improvements, providing a revised study to the students.

The course will make use of different teaching methods such as blended learning. However, due to the early stage of development only rough details regarding technology usage can be described. This technology usage will particular align with ideas of e-learning (cf. Section 3.2)

\section{Results}

In the following, we present results from our study. As argued in Section 2, we have chosen open questions to cater for the novelty of the work we investigate. Moreover, this gives the case makers the best opportunity to reflect on their cases, and to go beyond the questions. This provides us with broader insights than otherwise achievable.

\subsection{What we Asked}

The list of questions that were given to the case makers is shown in Figure 1. As suggested earlier, the questions are deliberately kept open, as it covers the breadth of the topics. We explicitly asked the participants to reflect on their case first, by summarizing it in their own words (1), and by scrutinizing whom they involve (2) and how the case is placed in relation to prior activities (3). These three questions provide us with the background of the cases, as summarized in Section 4.
1) Please briefly describe your case.

2) Please name main stakeholders of the case, and describe how their current situation is and how they will be affected by the work conducted as part of the case.

3) Please indicate to which extent the case replaces existing structures, tools and processes with digital means (i.e. technology).

4) Please describe in detail any technology employed as part of the cases.

5) Have any pedagogic concepts been employed when designing the case? Does the case built on prior work by others?

6) Please describe how you intend to engage citizens. Does technology aid this engagement? Could technology even be used to empower citizens?

7) How do you intend to evaluate the effectiveness of the work you carry out?

8) How do you think your work connects to the concept of social resilience?

9) Does your community follow a strategy for more resilience? (This includes large-scale initiatives such as the 100 Resilient cities as well as local, small-scale plans to achieve more resilience.)

Figure 1. The questions we asked in the study

Since we discuss technology as the enabler and mediator in this paper, we then asked for the technologies used in the cases (4). As the second precondition for the cases, we wanted to learn about pedagogical concepts (5). Then we asked for the combination of both topics, namely the influence of technology on citizen engagement (6). These three questions provide us with the concepts and tools used in the cases. The summary of analysing the replies is given in the following Section 5.2.

Finally, we asked the participants to reflect on their cases. They not only should scrutinize how their case's effectiveness could be evaluated (7) but also in how far they think it connects to the concept of resilience (8). Of course, in both cases we were interested to hear the participants view on how, especially since the possibility for an evaluation and a general connection to resilience should be preconditions for the cases. Finally, we wanted to see the case in the broader context. Therefore, we asked whether the community the case belongs to follows an explicit resilience strategy (9). These three questions provide us with ample possibilities to discuss the self-reflection of the cases. The summary is given in Section 5.3 


\subsection{Concepts and Tools}

The level of technological usage differs in the cases. Cases 1 and 3 make use of technological platforms to support learning. The activities would be much less efficient or less appealing if not carried out with technological support; however, the technology serves as a means to an end. As a particularity of the first case, the refugees might at one point get involved in the further development of the apps as actual developers.

Case 2 has much more maker-oriented usage of technology. It tries to seamlessly blend the usage of well-known apps such Instagram and widespread hardware such as tablets with custom apps and less common hardware such as smart light bulbs. Strictly speaking, the latter is even used out of the original purpose.

Due to the early stage of Case 4, usage is not fully clear. It likely will be somewhere in between the two extremes shown here.

The foundation in pedagogical concepts gives a mixed picture. Two cases have not used specific concepts or followed a way of combining innovative ideas with common sense. Case 4 is based on heavily involving teachers, thereby securing rigour regarding didactics. Case 2 is conceptually very sound, employing e.g. action learning and co-creation 1 . These concepts are not tried out from scratch but the work is based on prior experience with them.

For the engagement of citizens, technology support is vital in all cases. Typically, social media is used, in some of the cases in an integrated way (such as in the app developed for Case 1). Citizen should be addressed by providing appealing content. In Case 3, the addressees are not limited to citizens, as tourists ought to be included as well. It is therefore considered to provide content with added value, such as videos. In Case 2, the citizens in first line are kindergarten pupils. However, through making them resilient also their parents, relatives and neighbours can be engaged. This possibly includes people who otherwise can hardly be reached, e.g. because they do not (yet) speak the national language.

\subsection{Self-Reflection}

To our surprise, evaluation has been considered for all cases already. Typically, the involved stakeholders will meet and discuss progress and experiences. In some of the cases, work with questionnaires and other evaluation tools is planned. In Case 4, such materials are planned to be reused that have proven to be most effective. As part of Case 2, not classic evaluation is considered but rather collecting best practices is sought. This aligns well with the experimental nature of this case.

1. With regard to co-creation in the context of resilience, please also refer to [4].
As we had hoped due to our exchange with the case makers, social resilience is well considered in all cases. The actual way towards resilience differs a lot, though. In Case 1, it is achieved through the support of refugees and thereby both on a short-term, rather direct and on a long-term, rather indirect level. For Case 2, the effect on resilience is twofold. Pedagogues are supported in their work, especially in the work with children who might face social adversities. The children get self-consciousness and acquire a "community spirit". Vectoring is a specific aim in Case 3. If more people learn e.g. how to behave in case of natural disasters, an even greater number can be sensitized for such topics. Thereby, resilience is built in a strict bottomup fashion. Case 4 seeks to foster intercultural competence along with basic knowledge about resilience.

Our last question was the most challenging one. Only in one case a direct strategic connection is given; the project of Case 1 is embedded in the "municipal plan of gender equality, inclusion and diversity strategy". Two of the case maker's local governments heavily participate in resilience initiatives and engage in other research projects that seek to support governments or that has urban resilience as the main objective. However, the work on the cases is not embedded into such activities. On the one hand, this means that the cases have less backup from the local governments as would be desirable. On the other hand, it means that the cases are quite innovative and at least meet an environment where resources are available to try out innovative ways of facilitating resilience.

\section{Discussion}

The results allow for a discussion. We first present insights. Then, we name limitations of our work. Based on these, we propose questions that ought to be solved by future research and explain the next steps that we will take.

\subsection{Insights}

A general, positive assessment is that the topic of resilience is considered important in Scandinavian and Baltic cities. Local governments support initiatives. Moreover, individuals are highly motivated in treading new paths to learn what works - and what not. The attitude towards technology is practical: all case makers share an interest in technologymediation, in some cases even a quite enthusiastic one. However, all of them have been rather objective in this and did not seek to use technology for the sake of doing something "fancy" or to adhere to buzz words.

The cases illustrate that technology is not necessarily extensively used to engage citizens and to reach people that otherwise would hardly be reached. A finding therefore is the noteworthiness of trying out new activities. Neither of the cases uses many resources in term of time, budget,

Page 2337 
hardware in the broader sense, and venues. Cities, or more broader governments should thus be encouraged in trying out to build resilience in a bottom-up way. Reaching citizens must not be particularly complicated, as illustrated by all four cases. Interestingly, reaching citizens by proxy (such as parents through their children in a kindergarten) has been little discussed. This is considered in one of the cases only, and we are not aware of specific literature on this possibility. We deem the approach to be very appealing, though, and will follow up.

Fiddling with technology seems to be attractive, in particular to children. Therefore, we hope to see more makeroriented endeavours. However, from the experiences with the cases it is too early to propose this as a best practice.

As scientist, particularly as author of a paper that tackles experimental topics, we deem evaluation to be extremely important. Without properly assessing one's own work, insights can hardly be gained. Even worse, a continuous improvement is hindered. The effort all case makers put into considering the evaluation of their approaches underlines the seriousness they have in their work. This might be surprising, considering the to some degree informal nature that comes with the experimental, explorative, and evolutionary work. We deem a clear focus on measurability to be vital for any comparable attempts towards fostering resilience.

No clear insight can be drawn from the replies to our question about the embedding of cases in a resilience strategy. However, it can be concluded that resilience strategies need to get more attention. It would be interesting to learn whether such bottom-up approaches as shown in this paper will be effective for a city, or if it should rather follow a top-down approach. Possibly, a hybrid approach is most promising. We are confident that the four cases will have an impact in the four corresponding municipalities, and that the local governments will evaluate these endeavours positively. However, it is unclear whether it helps for such work if the city is engaged in bigger initiatives. Since we have both case makers with a strategy backing up the work, and not, we will need to evaluate further cases and wait for future activities to gain a clearer picture.

\subsection{Limitations}

Due to the novelty of the topic that we cover in this paper, and due to the iterative nature of the case development, our work has some limitations. The first limitation obviously comes from the nature of our project. We are working on cases, that are supposed to be transformed into regular activities and possibly also teaching materials for others. Thereby, they could in the long run support governments in the resilience endeavours. However, the cases retain a workin-progress status for a considerably amount of time to come. This does not hinder their assessment, as we are doing it in this paper. They should not be considered widespread, routine practice but rather as educated experiments and therefore handled with critical distance, though.

The second limitation lies in the evaluation of the cases. We are part of the underlying project and all work conducted within the scope of it has a qualitative nature. Therefore, the work is only partly generalizable. This does not decrease its suitability as a trailblazer, though.

The third limitation can be seen in the multi-topical and multi-disciplinary nature of the work we present here. The different topics alone are typically well understood (see also Section 3). Their combination can be ascertained to be less well understood, and the direction of this paper can draw from little existing work. This is typical for work that seeks to employ existing knowledge to conquer new areas. Nevertheless, it means that is not straightforward to include all viable sources and at the same time to delimit our work from other approaches. This setting also has the risk to place the work "between" communities, i.e. it draws from several areas but also contributes to several, thereby making a similarly small contribution from any single perspective.

As a fourth limitation, it needs to be kept in mind that this paper is the first one we seek to publish on the topic. Therefore, we need to explain background and underpinning with much detail and have less room to propose findings. This boundary is connected to the third one. However, this again is typical for a novel topic and we are confident that we could present several important insights in this work.

These limitations are noteworthy but they do not impede the value of our work. In fact, in conjunction with the above sketched open questions they provide the background for our future activities.

\subsection{Open Questions and Future Work}

As obvious from both the description of the cases, and the insights gained from our study, our work is at a rather early stage. This is owed to the novel combination of topics. Therefore, there are several open questions. However, we deem this as particularly welcomed, since these questions underline that the topic is worth investigating. We hope to engage more researchers to work into similar directions.

First, some insights could be given on the topic of engagement and empowerment, but many open questions remain. Future research needs to investigate many facets, as there are ample possibilities. It would be particularly interesting to learn if approaches and initiatives can be generically characterized and categorized, so that an abstract access to them can be provided.

Second, more focus on pedagogical concepts is needed. Obviously, developing cases without an elaborated pedagogical concept is possible, but unsurprisingly the case with the most advanced conceptual foundation is also the one that has made the most progress during the runtime of our project. Therefore, an open question is how pedagogical and didactic 
al concepts can be embedded with learning for resilience, and learning of resilience.

Third, we deem the topic of reaching citizens by proxy to be very relevant. Children who tell their parents e.g. about the correct behaviour in case of natural disasters and volunteers who inform their friends about positive experiences with refugees are two examples from our cases. It is easy to imagine further possibilities. However, the effectiveness of this is not understood, and there are no best practices that governments can employ. Just being able to imagine positive cases does not necessarily mean that governments should investigate options. Therefore, how to effectively utilize engagement by proxy is another open question.

Fourth, we would like to become able to draw more detailed conclusions. Ideally, the further work in the project will enable us to draw a more detailed picture of the relationship of technology, societal learning, and resilience. Possibly within the scope of the project, but definitely as a follow up result, a framework could be proposed. Moreover, it would be very valuable to propose framing conditions for each of the cases to allow for better comparability and generalization. This should include preconditions and postconditions, operational milestones, evaluation criteria, and similar observations. Such framing would not only allow for an easier overview of cases, but also serve towards their adaptability.

These open questions are also the foundation for our own future activities. In general, we will continue contributing to the underlying project from a scientific perspective. We will aim at advising regarding the coverage of resilience concepts in the cases while observing the effect of the cases on social and urban resilience as the same time.

More specifically, we will seek to make more comprehensive contributions to the theory. Additionally, we plan more empiric work. With the cases going into practical usage, we want to learn more about their effectiveness and would like to work qualitatively with case makers, case users (e.g. municipalities) and eventually also addressees (e.g. citizens). In the long run, we aim at a quantitative study to foster an understanding of the effects of technology-mediated learning on resilience.

\section{Conclusion}

In this paper, we have presented work on three topics in a novel-combination: technology, learning, and resilience. We have introduced four cases from a practice-focused research project that seek to enhance resilience through education. While the cases are quite different in nature, they share a technology-mediated approach towards learning.

We have used the cases for a self-reflecting study. The results from the study are quite diverse; They underline, however, the feasibility of - in particular municipal - initiatives to increase the resilience of the population with educational means. In the long-run, such initiatives could be an important contributing factor to social and urban resilience.

We could show that already insights can be draw from our work, although many open questions remain. We will tackle these in our future work.

\section{Acknowledgements}

We would like to thank the four case makers for their work on the cases and especially for taking the time to contribute the background of their cases to this paper. Moreover, we would like to thank Maren Andersen from VIFIN, Denmark, for leading the underlying project The Learning Society.

\section{References}

[1] "100 resilient cities," 2017. [Online]. Available: http: //www.100resilientcities.org/

[2] C. S. Holling, "Resilience and stability of ecological systems," Annual review of ecology and systematics, vol. 4, no. 1, pp. 1-23, 1973.

[3] J. Barth, K. Fietkiewicz, J. Gremm, S. Hartmann, A. Ilhan, A. Mainka, C. Meschede, and W. Stock, "Informational urbanism. a conceptual framework of smart cities," in Proc. 50th HICSS, 2017.

[4] C. Grimes, M. Sakurai, V. Latinos, and T. A. Majchrzak, "Co-creating communication approaches for resilient cities in europe: the case of the EU project SMR," in Proc. 14th ISCRAM. ISCRAM Association, 2017.

[5] J. Ahern, "From fail-safe to safe-to-fail: Sustainability and resilience in the new urban world," Landscape and Urban Planning, vol. 100, no. 4, pp. 341-343, 2011.

[6] M. Pelling, The vulnerability of cities: natural disasters and social resilience. Earthscan, 2003.

[7] W. T. Coombs, "Choosing the right words the development of guidelines for the selection of the "appropriate" crisisresponse strategies," Management Communication Quarterly, vol. 8, no. 4, pp. 447-476, 1995.

[8] L. Palen and S. B. Liu, "Citizen communications in crisis: Anticipating a future of ict-supported public participation," in Proceedings of the SIGCHI Conference on Human Factors in Computing Systems, ser. CHI '07. ACM, 2007, pp. 727736.

[9] M. Resnick and E. Rosenbaum, "Designing for tinkerability," Design, make, play: Growing the next generation of STEM innovators, pp. 163-181, 2013.

[10] R. K. Yin, Case study research: Design and methods. Sage Pub., 2013.

[11] J. Corbin and A. Strauss, "Grounded theory research: Procedures, canons and evaluative criteria," Zeitschrift für Soziologie, vol. 19, no. 6, pp. 418-427, 1990.

[12] K. M. Eisenhardt and M. E. Graebner, "Theory building from cases: Opportunities and challenges," Academy of management journal, vol. 50, no. 1, pp. 25-32, 2007.

[13] D. Smith and M. Fischbacher, "The changing nature of risk and risk management: The challenge of borders, uncertainty and resilience," Risk management, vol. 11, no. 1, pp. 1-12, 2009.

[14] T. M. Yates and A. S. Masten, Fostering the Future: Resilience Theory and the Practice of Positive Psychology. John Wiley \& Sons Inc, 2004, pp. 521-539. 
[15] I. Sommerville, Software Engineering, 9th ed. Pearson, 2011.

[16] C. Folke, S. Carpenter, T. Elmqvist, L. Gunderson, C. S. Holling, and B. Walker, "Resilience and sustainable development: building adaptive capacity in a world of transformations," AMBIO: A journal of the human environment, vol. 31, no. 5, pp. 437-440, 2002.

[17] "UNISDR terminology for disaster risk redution," United Nations International Strategy for Disaster Reduction (UNISDR) Geneva, Switzerland, 2009.

[18] M. Sakurai, T. A. Majchrzak, and V. Latinos, "Towards a framework for cross-sector collaboration: Implementing a resilience information portal," in Proc. 3rd Information Systems for Crisis Response and Management in Mediterranean Countries (ISCRAM-med), ser. Lecture Notes in Business Information Processing. Springer, 2017.

[19] L. Qvortrup, "E-learning - a knowledge theoretical approach," in Covergence - Fragmentation: Media Technology and the Information Society, P. Ludes, Ed. Intellect, 2006.

[20] B. S. Bell and J. E. Federman, "E-learning in postsecondary education," The Future of Children, vol. 23, no. 1, pp. 165185,2013

[21] S. Hrastinski, "Asynchronous and synchronous e-learning," Educause quarterly, vol. 31, no. 4, pp. 51-55, 2008.

[22] H. Coates, R. James, and G. Baldwin, "A critical examination of the effects of learning management systems on university teaching and learning," Tertiary Education \& Management, vol. 11, no. 1, pp. 19-36, 2005.

[23] S. Hrastinski, "The potential of synchronous communication to enhance participation in online discussions: A case study of two e-learning courses," Information \& Management, vol. 45, no. 7, pp. 499-506, 2008.

[24] F. Rennie and T. Morrison, E-learning and social networking handbook: Resources for higher education. Routledge, 2013.

[25] K. Ala-Mutka, D. Broster, R. Cachia, C. Centeno, C. Feijóo, A. Haché, S. Kluzer, S. Lindmark, W. Lusoli, G. Misuraca et al., "The impact of social computing on the eu information society and economy," JRC Scientific and Technical Report EUR, vol. 24063, 2009.

[26] J. Hamari, J. Koivisto, and H. Sarsa, "Does gamification work? - a literature review of empirical studies on gamification," in 2014 47th Hawaii International Conference on System Sciences, Jan 2014, pp. 3025-3034.

[27] P. Isenberg, N. Elmqvist, J. Scholtz, D. Cernea, K.-L. Ma, and H. Hagen, "Collaborative visualization: Definition, challenges, and research agenda," Information Visualization, vol. 10, no. 4, pp. 310-326, 2011.

[28] J. Gikas and M. M. Grant, "Mobile computing devices in higher education: Student perspectives on learning with cellphones, smartphones \& social media," The Internet and Higher Education, vol. 19, pp. 18 - 26, 2013.

[29] E. T. Welsh, C. R. Wanberg, K. G. Brown, and M. J. Simmering, "E-learning: emerging uses, empirical results and future directions," International Journal of Training and Development, vol. 7, no. 4, pp. 245-258, 2003.

[30] A. A. Al-Qahtani and S. E. Higgins, "Effects of traditional, blended and e-learning on students' achievement in higher education," Journal of computer assisted learning, vol. 29, no. 3, pp. 220-234, 2013.

[31] T. A. Majchrzak and C. A. Usener, "Evaluating E-Assessment for Exercises that Require Higher-Order Cognitive Skills," in Proceedings 45th Hawaii International Conference on Systems Science (HICSS-45). IEEE Computer Society, 2012, pp. 48-57.

[32] P. Tschakert and K. Dietrich, "Anticipatory learning for cli- mate change adaptation and resilience," Ecology and society, vol. 15, no. 2, 2010.

[33] K. Sandvik, "Lifelong learning: developing methods and practices for future societies," 2018, fortcoming.

[34] B. K. Litts, "Making learning: Makerspaces as learning environments," $\mathrm{Ph} . \mathrm{D}$. dissertation, The University of WisconsinMadison, 2015.

[35] B. Bevan, J. Ryoo, M. Shea, L. Kekelis, P. Pooler, E. Green, N. Bulalacao, E. McLeod, J. Sandoval, and M. Hernandez, Making as a Strategy for Afterschool STEM Learning: Report from the Californian Tinkering Afterschool Network Research-Practice Partnership. The Exploratorium, 2016.

[36] K. Peppler, E. Halverson, and Y. B. Kafai, Makeology: Makerspaces as learning environments. Routledge, 2016, vol. 1.

[37] C. Dixon and L. Martin, "Make to relate: Narratives of, and as, community practice," in International Conference of the Learning Sciences, 2014.

[38] H. Neergaard and D. R. Christensen, "Breaking the waves: Routines and rituals in entrepreneurship education," Industry and Higher Education, vol. 31, no. 2, pp. 90-100, 2017.

[39] C. J. Bonk, R. A. Wisher, and M. L. Nigrelli, "Learning communities, communities of practice: Principles, technologies, and examples," in Learning to collaborate, collaborating to learn, K. Littleton, Ed. Nova Science Publishers Hauppauge, NY, 2004, ch. 12, pp. 199-219.

[40] K. Sandvik, "Courses as research and students in the roles as researchers. a case study," in DUNK17 - Dansk Universitetspadagogisk Netvark's annual conference, Vingsted Hotel og Konferencecenter 30.-31. May, 2017.

[41] "Podio," 2017. [Online]. Available: https://podio.com/ 